\title{
Tomurcuk Gül Yardımıyla Keten Kumaşların Renklendirilmesi
}

\author{
${ }^{1}$ Fazlihan YILMAZ \\ Özet \\ ${ }^{1}$ Atatürk Üniversitesi, Tekstil ve Moda Tasarımı Bölümü, Erzurum, TÜRKIYYE
}

Bilindiği üzere bitkisel kaynak kullanımı son günlerde popüler hale gelmiştir. Özellikle tüketicilerin doğal ürünlere olan ilgisinden dolayı her sektörde üreticiler doğal kökenli ürün kullanımını ön plana almaktadırlar. Günümüzdeki bu durum da göz önüne alındığında yapılan bu çalışmada bir bitkisel kaynağın tekstil boyamacılı̆̆ında kullanımı araştırılmıştır. Çalışma kapsamında yapılan boyama denemelerinde bitkisel kaynak olarak tomurcuk gül kullanılmıştır. Tekstil mamulü olarak ise $\% 100$ keten kumaş seçilmiştir. Denemelerde tomurcuk gül direkt olarak kullanılmıştır. Yani herhangi bir ön işlem görmemiş̧ir. Mordan maddesi kullanımı olmadan boyama denemesi gerçekleştirilmiştir. Ayrıca 5 farklı mordan maddesi kullanılarak da boyamalar yapılmıştır. Denemelerde kullanılan mordan maddesi konsantrasyonu ise $\% 3$ olarak ayarlanmıştır. Boyama işlemlerinde kullanılan mordan maddeleri ise; Çinko klorür $\left(\mathrm{ZnCl}_{2}\right)$, potasyum dikromat $\left(\mathrm{K}_{2} \mathrm{Cr}_{2} \mathrm{O}_{7}\right)$, demir II sülfat $\left(\mathrm{FeSO}_{4} \cdot 7 \mathrm{H}_{2} \mathrm{O}\right)$, kalay II klorür $\left(\mathrm{SnCl}_{2} .2 \mathrm{H}_{2} \mathrm{O}\right)$, bakır II sülfat $\left(\mathrm{CuSO}_{4} .5 \mathrm{H}_{2} \mathrm{O}\right)$ dır. Boyama işlemlerinde flotte oranı 1:40 ayarlanmış ve birlikte mordanlama yöntemine göre denemeler gerçekleştirilmiştir. Boyama işleminden sonra kumaş numuneleri yıkama işlemine tabii tutulmuştur. Son olarak, kurutma adımıyla birlikte boyanmış olan kumaş numunelerinin CIELAB ( $L^{*}, a^{*}, b^{*}, C^{*}$ ve $h^{\circ}$ ) ve K/S değerleri spektrofotometre yardımıyla ölçülmüş ve bunlara ek olarak 1şık ve yıkama haslığı testleri de gerçekleştirilmiştir. Sonuç olarak ise tomurcuk gülün keten kumaşları renklendirebileceği ve yeterli haslık değerlerini gösterebileceği tespit edilmiştir.

Anahtar Kelimeler: Tomurcuk gül, Tekstil, Renk, Doğal boya, Haslık.

\section{Coloring of Linen Fabrics by Using Bud of Rose}

\author{
${ }^{1}$ Fazlihan YILMAZ \\ ${ }^{1}$ Department of Textile and Fashion Design, Atatürk University, Erzurum, TURKEY
}

\begin{abstract}
As it is known, the use of herbal resources has become popular recently. Producers in every sector prioritize the use of products of natural origin, especially because of the consumers' interest in natural products. Considering this situation today, the use of a herbal source in textile dyeing was investigated in this study. In the dyeing experiments carried out within the scope of the study, bud of rose was used as a herbal source. As a textile product, $100 \%$ linen fabric was chosen. In the experiments, bud of rose was used directly. In other words, it has not been pretreated. Dyeing experiment was carried out without the use of mordant material. In addition, dyeings were made using 5 different mordant materials. The concentration of mordant used in the experiments was set at 3\%. Mordant materials used in dyeing processes are Zinc chloride $\left(\mathrm{ZnCl}_{2}\right)$, potassium dichromate $\left(\mathrm{K}_{2} \mathrm{Cr}_{2} \mathrm{O}_{7}\right)$, iron II sulfate $\left(\mathrm{FeSO}_{4} \cdot 7 \mathrm{H}_{2} \mathrm{O}\right)$, tin II chloride $\left(\mathrm{SnCl}_{2} .2 \mathrm{H}_{2} \mathrm{O}\right)$, copper II sulfate $\left(\mathrm{CuSO}_{4} .5 \mathrm{H}_{2} \mathrm{O}\right)$. In dyeing processes, the ratio of liquor was set to 1:40 and experiments were carried out according to the together mordanting method. After dyeing, fabric samples were subjected to washing. Finally, along with the drying step, the CIELAB ( $\mathrm{L}^{*}, \mathrm{a} *, \mathrm{~b}$ ${ }^{*}, \mathrm{C} *$ and $\mathrm{h}^{\circ}$ ) and $\mathrm{K} / \mathrm{S}$ values of the dyed fabric samples were measured with the aid of a spectrophotometer and in addition, light and washing fastness tests were carried out. As a result, it has been determined that the bud of rose can color linen fabrics and show sufficient fastness values.
\end{abstract}

Keywords: Bud of rose, Textile, Colour, Natural dye, Fastness.

*Corresponding author: Fazlıhan YILMAZ Address: Department of Textile and Fashion Design, Atatürk University, Erzurum, TURKEY. E-mail address: fazlihan.yilmaz@atauni.edu.tr, Phone: +905519079484 


\section{Giriş}

Türk milletinin kültür ve sanat tarihi incelendiğinde, oldukça eski zamanlarda dahi insanların yeteneklerini kullanarak doğadaki farklı malzemelerden elde edilen hammaddeleri değerlendirdiği görülmektedir. İnsanlar yaşadıkları coğrafya, yaşam tarzı ve yeteneklerine göre doğal kaynakları kullanarak dokuma, örme, dikiş, boya, işleme gibi çeşitli yüzey oluşturma yöntemleri ile ihtiyaçlarına yönelik tekstil yüzeyleri oluşturmuşlardır [1].

Doğal boyamacılık tarihi oldukça eski zamanlara dayanmaktadır. Belli bir dönemde popülaritesini kaybetse de günümüzde çevreci yaklaşımlarla birlikte yeniden adından söz edilir hale gelmiştir [2]. Çünkü sentetik boyarmaddelerin toksin, kanserojen ve biyolojik olarak parçalanabilir olmaması, günümüzde doğal boyarmaddelerin kullanımını popüler hale getirmektedir [3]. Bitkisel boyalar; Renk veren bitkilerin yaprak, çiçek, kozalak, gövde kabukları, kök, sürgün vb. kısımlarından elde edilmektedir. Bitkisel boyarmaddelerle doğrudan boyama yapılabildiği gibi, aynı zamanda yardımcı maddelere de ihtiyaç duyulmaktadır. Mordan adı verilen bu maddeler, boyarmaddenin liflere daha iyi tutunmasını, iyi bir renk haslığı ile aynı bitkiden farklı renk tonları elde edilmesini sağlamaktadır [4]. Çok geniş bir floraya sahip olan (10.000'den fazla bitki türü) Anadolu'daki boyamacılık işlemi farklı kültür alışverişi sonucunda çeşitli boyacılık yöntemlerini de kazanmış olup, Anadolu'da geniş bir kültür haline gelmiştir [5].

Güller (Rosa spp.) Rosaceae familyasının hoş kokulu, güzel görünüşlü bitkilerinin cinsi olarak bilinir. Oldukça eski bir geçmişe sahip olan gül, güzel kokusu ve cezbedici güzelliğiyle çağlar boyunca insanlar tarafından yetiştirilmiş ve kullanılmıştır [6]. Gül tarımı, Göller Bölgesi'nde önemli bir yer tutmaktadır ve birçok ailenin de geçim kaynağını sağlamaktadır. Isparta yöresinde yaklaşık 8,000 çiftçi ailesi gül üretimiyle uğraşmaktadır [7]. Gül Mayıs-Haziran aylarında çiçek açar ve hasadı 40-45 gün sürer. Bu dönemde gül çiçekleri günlük olarak toplanır ve üretim tesislerinde işlenerek gül suyu ve gül yağı gibi ürünlere dönüştürülür [8].

Yapılan bu çalışmada gülün bilinen kullanım alanlarından farklı bir alan olan tekstil boyamacılığında kullanılıp kullanılamayacağı araştırılmıştır.

\section{Materyal - Metod}

Boyama denemelerinde \%100 keten kumaş kullanılmıştır. Denemelerde kullanılan keten kumaş boyama işlemine hazır halde tedarik edilmiştir.

Keten kumaşların renklendirilme çalışmalarında, bitkisel boyarmadde kaynağı olarak Şekil 1'de görseli bulunan tomurcuk gül kullanılmıştır. 


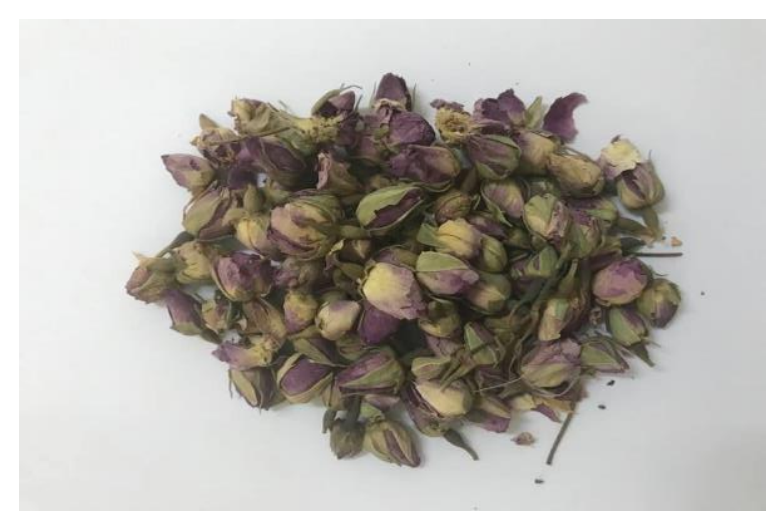

Şekil 1. Tomurcuk Gül

Şekil 1'de görseli bulunan tomurcuk gül, boyama işlemlerine başlanılmadan önce öğütülmüştür. Öğütülmüş olan bu kısım boyama denemelerinde direkt olarak kullanılmıştır. Yani herhangi bir ön işlem gerçekleştirilmemiştir.

Boyama denemelerinde 5 farklı mordan maddesi kullanılmıştır. Bunlar; Çinko Klorür $\left(\mathrm{ZnCl}_{2}\right)$, Potasyum Dikromat $\left(\mathrm{K}_{2} \mathrm{Cr}_{2} \mathrm{O}_{7}\right)$, Demir II Sülfat $\left(\mathrm{FeSO}_{4} .7 \mathrm{H}_{2} \mathrm{O}\right)$, Kalay II Klorür $\left(\mathrm{SnCl}_{2} .2 \mathrm{H}_{2} \mathrm{O}\right)$, Bakır II Sülfat $\left(\mathrm{CuSO}_{4} .5 \mathrm{H}_{2} \mathrm{O}\right)$ dir. Bunlara ek olarak mordan maddesi kullanımı olmadan da keten kumaşın boyama denemesi gerçekleştirilmiştir.

Boyama denemelerinde flotte oranı 1:40 olarak ayarlanmıştır. Mordan konsantrasyonu ise \%3 olarak seçilmiştir. Ayrıca boyama işlemlerinde bitkisel boyarmadde ağırlığı kumaş ağırlığıyla eşit (1:1) olarak ayarlanmıştır. Yani 2 gr keten kumaş için 2 gr bitkisel boyarmadde kaynağı alınmıştır.

Boyama işlemlerinin hepsi Şekil 2 gösterilen laboratuvar tipi numune boyama makinasında gerçekleştirilmiştir. Boyama denemelerine $50{ }^{\circ} \mathrm{C}$ 'de başlanılmış ve bu sıcaklıkta 10 dakika boyunca işlem devam etmiştir. Ardından 40 dakikada $120^{\circ} \mathrm{C}^{\prime}$ ye çıkılmıştır. Bu sıcaklıkta 55 dakika boyunca boyama işlemi gerçekleştirilmiş ve ardından yıkıma işlemiyle birlikte boyanmış olan kumaş numuneleri kuruması için oda sıcaklığında bekletilmiştir.

Kurumuş boyalı keten kumaş numunelerinin CIELAB (L*, $a^{*}, b^{*}, C^{*}$ ve $h^{\circ}$ ) ve K/S değerleri spektrofotometre yardımıyla ölçülmüş ve bunlara ek olarak 1şık (ISO 105-B02 standardına göre) [9] ve yıkama (ISO 105-C10standardına göre) [10] haslığı testleri de gerçekleştirilmiştir. Elde edilen sonuçlar ise 3. Bölümde tablolar halinde sunulmuştur. 


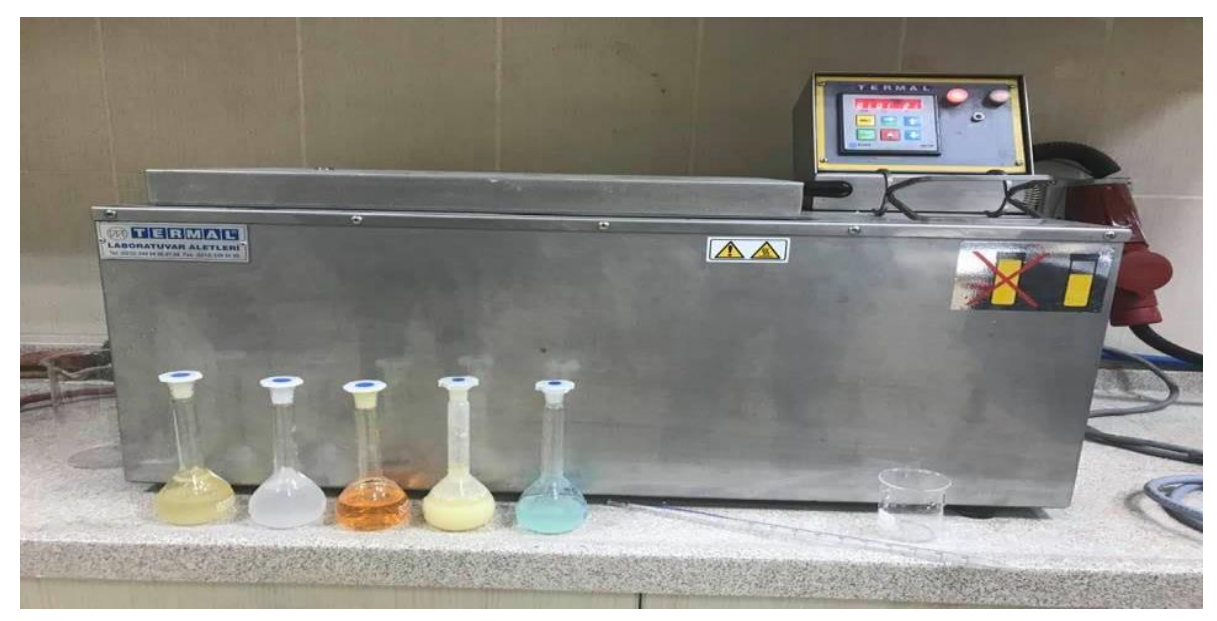

Şekil 2. Laboratuvar Tipi Numune Boyama Makinası

\section{Bulgular - Tartışma}

Keten kumaş numunelerinin renklendirilmesi işleminde tomurcuk gül kullanılmıştır. Bu boyama denemelerinde 5 farklı mordan maddesinin yanı sira mordan maddesi kullanımı olmadan da boyama denemesi gerçekleştirilmiştir. Bu boyama işlemleri neticesinde elde edilen renk değerleri Tablo 1'de sunulmuştur.

Tablo 1. Keten Kumaşların Tomurcuk Gül Yardımıyla Boyanması Sonucunda Elde Edilen CIELAB (L*, a*, b*, $\mathrm{C}^{*} \mathrm{ve} \mathrm{h}^{\circ}$ ) ve K/S değerleri

\begin{tabular}{|l|c|c|c|c|c|c|}
\hline \multirow{2}{*}{ Mordan tipi } & & \multicolumn{5}{|c|}{ CIE L*a*b* (D65) } \\
\cline { 2 - 7 } & K/S & $\mathrm{L}^{*}$ & $\mathrm{a}^{*}$ & $\mathrm{~b}^{*}$ & $\mathrm{C}^{*}$ & ho \\
\hline Çinko Klorür & 2,77 & 70,56 & 0,89 & 21 & 21,02 & 87,57 \\
\hline Potasyum Dikromat & 1,72 & 72,17 & 2,22 & 22,29 & 22,4 & 84,32 \\
\hline Demir II Sülfat & 2,69 & 69,3 & 1,4 & 19,43 & 19,48 & 85,89 \\
\hline Kalay II Klorür & 2,22 & 69,88 & 1,97 & 17,89 & 18 & 83,71 \\
\hline Bakır II Sülfat & 4,28 & 63,85 & 2,38 & 23,55 & 23,67 & 84,22 \\
\hline Mordansız & 2,59 & 68,1 & 1,93 & 17,46 & 17,57 & 83,69 \\
\hline
\end{tabular}

Tablo 1'deki K/S değerlerine bakıldığında en yüksek değerin 4,28 ile bakır II sülfat mordan maddesi kullanılarak yapılan boyama deneyinde elde edildiği görülürken, en düşük değerin ise 1,72 olarak potasyum dikromat mordan maddesi kullanılarak yapılan boyama işleminde tespit edildiği görülmüştür. Mordan maddesiz yapılan boyama işleminde ise K/S değeri 2,59 olarak karşımıza çıkmaktadır. Yine Tablo 1'deki L* değerleri incelendiğinde, en yüksek değer 72,17 olarak 
karşımıza çıkmaktadır. Bu değere potasyum dikromat mordan maddesi ile ulaşılmıştır. En düşük değer ise 63,85 dir. Bu değere ise boyama işleminde bakır II sülfat mordan maddesi kullanılarak ulaşılmıştır. Mordan maddesi kullanılmadan yapılan boyama denemesinde ise L* değeri 68,1 olarak tespit edilmiştir.

Tomurcuk gül kullanılarak yapılan boyama denemelerinde kahverengi tonlarının elde edildiği görülmüştür. Örneğin; Bakır II sülfat mordan maddesi kullanılarak yapılan boyama denemesinde, $\mathrm{a}^{*}=2,38, \mathrm{~b}^{*}=23,55$ ve ho $=84,22$ olarak bulunmuştur. Yapılan bu boyama deneyinde renk kahverengi olarak tespit edilmiştir. Bir başka boyama işleminde ise çinko klorür mordan maddesi kullanılarak açık kahverengi gözlemlenmiştir. Burada ise $\mathrm{a}^{*}=0,89, \mathrm{~b}^{*}=21$ ve ho $=87,57$ olarak bulunmuştur.

Tomurcuk gül kullanılarak yapılan boyama denemeleri sonucunda boyanmış olan keten kumaşların 1 şık ve yıkama haslığı testleri de yapılmıştır. Elde edilen sonuçlar ise Tablo 2'de sunulmuştur.

Tablo 2. Tomurcuk Gül İle Boyanmış Keten Kumaşların Işık ve Yıkama Haslığı Test Sonuçları

\begin{tabular}{|c|c|c|c|}
\hline Mordan Maddesi & $\begin{array}{c}\text { Işık } \\
\text { Haslığı }\end{array}$ & \multicolumn{2}{|c|}{$\begin{array}{l}\text { Yıkama } \\
\text { Haslığı }\end{array}$} \\
\hline \multirow[b]{2}{*}{ Çinko Klorür } & \multirow[b]{2}{*}{5} & $\mathrm{R}$ & 4 \\
\hline & & $\mathrm{L}$ & 5 \\
\hline \multirow[b]{2}{*}{ Potasyum Dikromat } & \multirow[b]{2}{*}{$4-5$} & $\mathrm{R}$ & $4-5$ \\
\hline & & $\mathrm{L}$ & 5 \\
\hline \multirow[b]{2}{*}{ Demir II Sülfat } & \multirow[b]{2}{*}{$5-6$} & $\mathrm{R}$ & $4-5$ \\
\hline & & $\mathrm{L}$ & 5 \\
\hline \multirow[b]{2}{*}{ Kalay II Klorür } & \multirow[b]{2}{*}{$4-5$} & $\mathrm{R}$ & 4 \\
\hline & & $\mathrm{L}$ & 5 \\
\hline \multirow[b]{2}{*}{ Bakır II Sülfat } & \multirow[b]{2}{*}{$5-6$} & $\mathrm{R}$ & 5 \\
\hline & & $\mathrm{L}$ & 5 \\
\hline \multirow{2}{*}{ Mordansiz. } & \multirow{2}{*}{5} & $\mathrm{R}$ & 4 \\
\hline & & $\mathrm{L}$ & $4-5$ \\
\hline
\end{tabular}

Tablo 2 incelendiğinde, tomurcuk gül ile boyanmış keten kumaşların 1şık haslığı açısından iyi değerlerin elde edildiği tespit edilmiştir. Farklı boyama deneyleri için birbirine yakın 1şık haslığ sonuçlarının elde edildiği de görülmüştür. Aynı şekilde yıkama haslığı değerleri incelendiğinde de yine farklı boyama deneylerinde hem renk değişimi hem de referans kumaşı kirletme açısından birbirine yakın sonuçların elde edildiği gözlemlenmiştir. Yıkama haslığı deneyinde referans olarak yine keten kumaş kullanılmıştır. 


\section{Sonuç}

Gülün birçok alanda kullanımı söz konusudur. Yapılan bu çalışmada ise tomurcuk gülün keten kumaşların renklendirilme işlemlerinde kullanılıp kullanılmayacağ kapsamında boyama denemelerinde 5 farklı mordan maddesi kullanılmıştır. Buna ek olarak mordan maddesi kullanılmadan da boyama işlemleri gerçekleştirilmiştir. Boyama denemeleri sonucunda tomurcuk gülün, çalışma kapsamında kullanılan reçete yardımıyla keten kumaşları renklendirebileceği tespit edilmiştir. Ayrıca farklı mordan maddesi kullanılarak farklı tonlarda rengin elde edilebileceği gözlemlenmiştir. Yapılan haslık testleri sonucunda da tomurcuk gül ile renklendirilmiş keten kumaşların kullanım açısından gerekli haslık özelliklerini de sağladığ tespit edilmiştir.

\section{Kaynaklar}

[1] Akpınarlı HF, Üner İ. Geleneksel Tekstillerin Özellikleri ve Çeşitleri. Pamukkale Üniversitesi Sosyal Bilimler Enstitüsü Dergisi 2019; 34: 133-145.

[2] Yılmaz F. Doğal Boyamacılık Kapsamında Altın Otu (Helichrysum Arenarium) İle Yünlü Kumaşların Boyanması. Sanat Dergisi 2020; 35: 102-108.

[3] Eyüpoğlu Ş. Yabani Ekin Çiçeğinden Elde Edilen Doğal Boya İle Keten Kumaşın Farklı Yöntemlere Göre Boyanma Özelliklerinin İncelenmesi. Düzce Üniversitesi Bilim ve Teknoloji Dergisi 2020; 8: 317-325.

[4] Başaran FN, Aydın Ş. Nar (Punica Granatum L.) Bitkisinin Doğal Mordanlarla Boyama ve Haslık Değerleri. IBAD Sosyal Bilimler Dergisi 2019; 5: 397-406.

[5] Kadığlu İ, Şin B, Kınalı B. Tokat İlinde Görülen Bazı Bitkilerin Boya Bitkisi Olarak Kullanım Olanakları. Turkish Journal of Weed Science 2019; 22(1): 7-15.

[6] Özcan K, Dönmez İE. Isparta Güneykent Bölgesinde Yetişen Gül Odununun (Rosa Damascena Mill.) Kimyasal Bileşimi ve Lif Özellikleri. Türkiye Ormancılık Dergisi 2018; 19(4): 442-446.

[7] Gökdoğan O, Demir F. Isparta Yöresindeki Gül Yetiştiriciliği Yapılan İşletmelerin Tarımsal Mekanizasyon Düzeyi. Adnan Menderes Üniversitesi Ziraat Fakültesi Dergisi 2011; 8(2): 1-6.

[8] Çancı MB, Kılıç M. Treatment of Rose Processing Wastewater by Sunlight/TiO2 Photocatalysis Process. Bilge International Journal of Science and Technology Research 2020; 4(1): 1-6.

[9] ISO 105-B02: (1994), Textiles-Tests for color fastness - Part B02: Color fastness to artifical light, International Organization for Standardization, Brussels, Belgium 
[10] ISO 105-C10: (2006), Textiles-Tests for color fastness-Part C10: Color fastness to washing with soap or soap and soda, Test Condition: Test A (1), International Organization for Standardization, Geneva, Switzerland. 